\title{
Research on Energy Issues and Solutions
}

\author{
Xuehan Hou, Junyao Xu \\ Mathematic Department, University of Liverpool, Liverpool
}

Keywords: energy usage; energy production; PCA;

\begin{abstract}
The energy usage and production are two main aspects of the energy situation for a state. Therefore, to solve the energy problem and to achieve the common target for Arizona, California, New Mexico and Texas, it is essential to describe the energy situation from both aspects of consumption and production. This paper conducted PCA analysis for each state from both consumer and production perspectives and proposed a solution. In the future, four governments should establish a cooperative relationship to focus on the advantage of each state and establish a standard for energy usage for four states to solve the energy problem.
\end{abstract}

\section{Introduction}

The strength of national economies derives from a large number of factors, the most important of which is the acquisition and effective use of energy resources. Given its critical nature, it is imperative for states and nations to cooperate to further development in this field, particularly with regards to the problems inherent to their respective regions, i.e. types of industry specific to the region, geographical challenges, etc. One such cooperative movement is the Western Interstate Energy Compact (WIEC), formed by 12 U.S. states in 1970 - the primary focus of which lies in the domain of nuclear power technologies, to cooperate on and adopt appropriate policies and standards for its management and development. The solutions proposed in this paper will offer an insight to handle the energy resources related data set, which collected from four U.S. states border with Mexico. We use the ARIMA model and the VAR model to analyse and predict the state of energy in the four states and to give the differences in renewable resources between the four states.

\section{Data Analysis}

For this problem, we have 605 variables related to energy resources, which means there is a diversity of inputs with various types. Moreover, some of the variables independently described according to the official supplementary material, such as the TPOPP which represents the resident population including the Armed Forces residing in each state. However, some may derive from other variables. For example, the residual fuel oil consumed by the electric power sector measures by Billion Btu (RFEIB) equals to the variable REFIP times by 6.287, which uses a thousand barrels as the unit of fuel oil consumption. Considering this, we must carefully analyse the data set to dig out the meaning of each column and separate those variables into different groups.

After a brief examination of the data set, we made two sets of criteria for categorising the data within each of the four U.S. states. One criterion focuses on the energy usage of five main sectors: the industrial sector, the transportation sector, the residential sector, the commercial sector and the electric power sector. For another one, we separated the energy usage behaviour into two parts: energy production and energy consumption. 


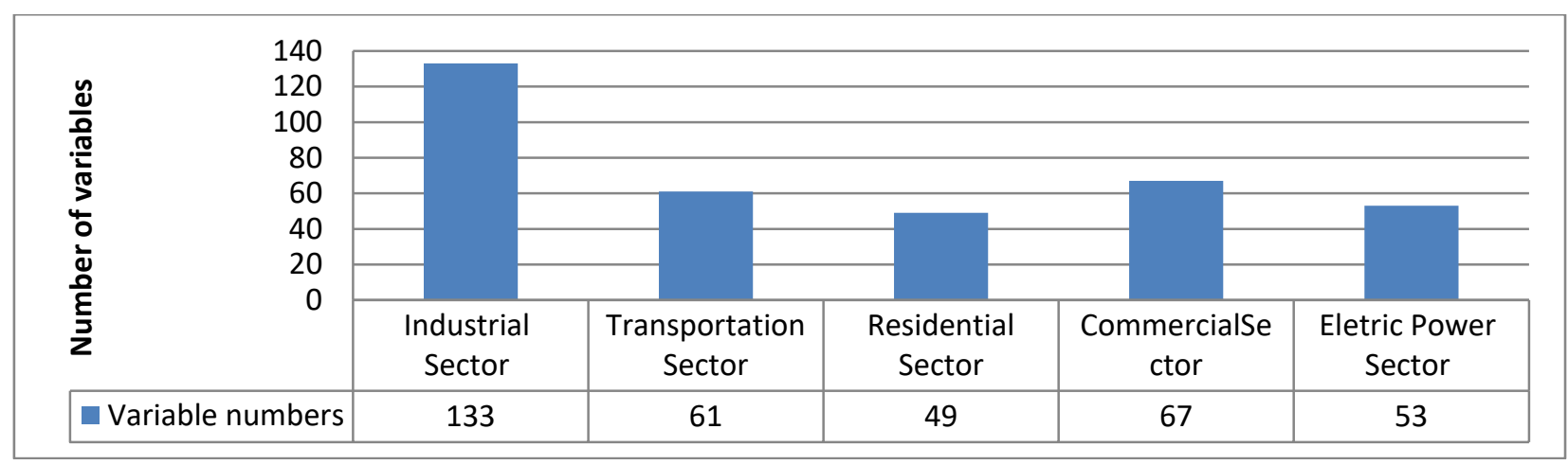

Figure 1 . The number of variables selected among each sectors

The above chart summarizes the number of variables in each category under different sectors. From the result, the industrial sector appears to have the highest number of variables, while the residential sector has the lowest.

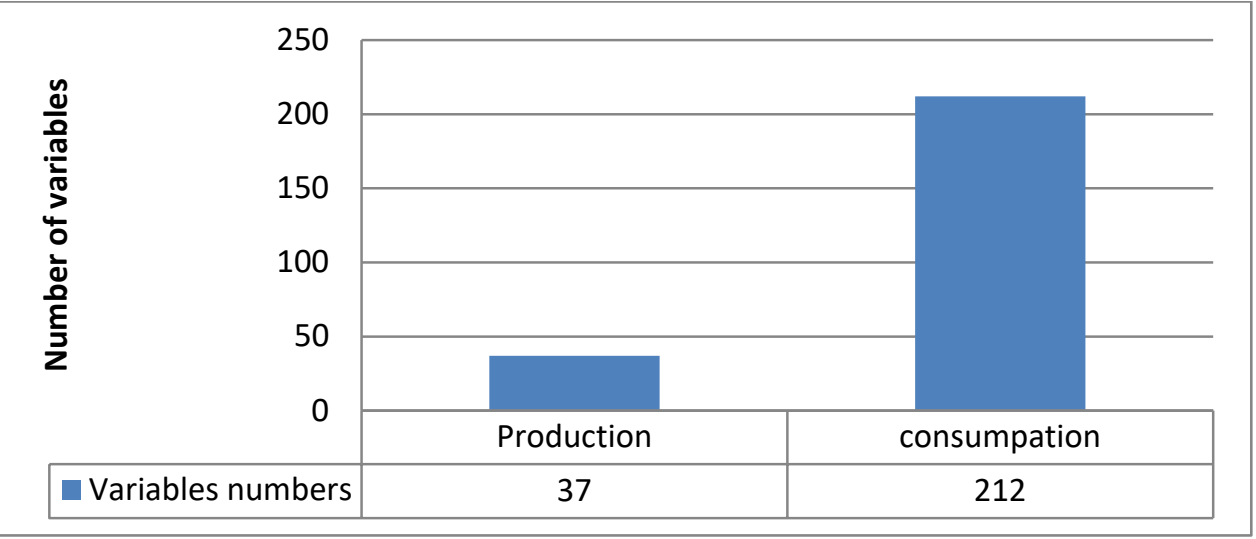

Figure 2. The number of variables related to energy production and consumption

As described in figure 2, the number of variables related to energy production and consumption presented clearly.

Too many variables which cause the problem that the energy profile is hard to be defined. To solve this problem, we defined a new assessment model that is built based on PCA (principal component analysis) selection. The most important part of our model is that we extracted the contribution score of every variable in different principal components, and the combination of those variables with highest contribution scores can be used to explain the energy profile of that state. We calculated the contribution scores of energy production and consumption related variables in each of four states, as the sector usage situation shall reflect in those high contribution variables.

Using PCA for analysis, it is obvious that the top 10 consumption of energy resources in AZ State are all related to oil and its derivative products, and the main resource it produced is electricity, both from wind energy and water energy. The consumption of energy resources in CA State are related to coal and fuel oil, but different from AZ state, and the main resource it produced is electricity, etc.

\section{Modelling and Result}

\subsection{VAR Modeling}

In order to improve the result, we built another time series model using the VAR (vector auto-regression) model for all the indicators from one aspect. Because the input or the independent variables are the indicators which is the principal components obtained by PCA technique, the covariance of different indicators are not equal to zero which means the indicators are not independently distributed and simply modelling the individual indicator may cause the inaccuracy and bias. Therefore, the VAR model takes the correlation between indicators into considerations.

Assumptions: 
A1: The covariance matrix of the indicators is not equal to zero which means the explanatory variables are correlated.

A2: The indicators which are entered into model should be the stationary time series.

A3: The residual should be the white noise and there is no auto-regression among residuals.

A4: All the explanatory variables are only auto-correlated to each other with only time lag 1 which means the current energy situation will not affect more than one year.

Modelling:

The VAR model built is described as follow in the equation:

$$
\left[\begin{array}{c}
\text { Indicator_1 } \\
\text { Indicator_2 } t \\
\ldots
\end{array}\right]=\left[\begin{array}{c}
\mathrm{C}_{1} \\
\mathrm{C}_{1} \\
\ldots
\end{array}\right]+\left[\begin{array}{ccc}
\mathrm{A}_{11} & \mathrm{~A}_{12} & \ldots \\
\mathrm{A}_{21} & \mathrm{~A}_{22} & \ldots \\
\ldots & \ldots & \ldots
\end{array}\right]\left[\begin{array}{c}
\text { Indicator_1 } 1_{t} \\
\text { Indicator_2 } t \\
\ldots
\end{array}\right]+\left[\begin{array}{c}
\mathrm{e}_{1 \mathrm{t}} \\
\mathrm{e}_{2 \mathrm{t}} \\
\ldots
\end{array}\right]
$$

In the above equation, the error term e is the white noise with mean zero and constant variance. The explanatory variables (indicators) are all non-stationary time series. Therefore, the lag one differencing were conducted to satisfy the Assumption Two. After using R to estimate the parameters in the model, we obtain two VAR models for each state from the aspects of consumption and production respectively.

After the principal component analysis, the main components of each year calculated for each state which can consider as the indicators of the energy situation from different aspects. For each state, the indicators consist of the energy profile as we defined before. To explain features of the energy situation for four states, two aspects (consumption and production) analyzed through the time series model.

\subsection{Result}

The VAR (1) model is applied both for the consumption and production aspect, we selected variables and combined them into indicators to reflect the general energy use situation. These variables considered as the energy profile specifically for Arizona. After differencing the data by lag one, the input variables became stationary which is correspond to the assumption of the VAR model. The ADF tests are conducted to test the stationary of data.

After building the VAR model by using the differencing data of lag one, the fitted value for past 50 years shown in the figure above. As we can see from the figure, each indicator represented in three sub-figures. Firstly, the time series plot shows the true value and the fitted value in black and blue dotted lines respectively as well as the residual plot shown below. The ACF and PACF plot shown in sub-figure left and right. Generally speaking, the VAR (1) model can fit the value adequately, which can describe the movement of the data in the past 50 years. Also, from the ACF and PACF plot, the residuals model did not have the auto-correlation and shown the pattern of the white noise, which also corresponds to our assumptions. The results for each state shown below:

\subsubsection{Arizona}

For Arizona, the overall consumption of energy is high and, in the future, there is a trend of increase of the total amount of energy consumption. For the energy production, although the current energy is not as much as other states, the new and clean energy production industry is developing such like wind energy. The forecasting results for 2025 and 2050 of the energy profile are shown below:

\begin{tabular}{|l|l|l|l|l|l|}
\hline Consumption & 2025 & 2050 & Production & 2025 & 2050 \\
\hline Indicator_1 & 7.17 & -29.86 & Indicator_1 & $-1.31 \mathrm{e}+05$ & $-4.60 \mathrm{e}+12$ \\
\hline Indicator_2 & -11.11 & -2.96 & Indicator_2 & $2.79 \mathrm{e}+05$ & $1.96 \mathrm{e}+13$ \\
\hline Indicator_3 & -15.36 & -22.92 & Indicator_3 & $8.53 \mathrm{e}+05$ & $2.99 \mathrm{e}+13$ \\
\hline Indicator_4 & 33.76 & 45.37 & Indicator_4 & $-1.43 \mathrm{e}+05$ & $-5.04 \mathrm{e}+12$ \\
\hline Indicator_5 & 6.26 & 8.89 & Indicator_5 & $-2.15 \mathrm{e}+05$ & $-7.57 \mathrm{e}+12$ \\
\hline Indicator_6 & 2.69 & 0.84 & & & \\
\hline Indicator_7 & 0.53 & 0.22 & & & \\
\hline
\end{tabular}




\subsubsection{California}

California seems to have better energy profile compared to Arizona as the energy consumption in 2025 and 2050 is less and for the production aspect, the renewable and cleaner energy will become larger compared to the current status. The forecasting results are shown below:

\begin{tabular}{|l|l|l|l|l|l|}
\hline Consumption & 2025 & 2050 & Production & 2025 & 2050 \\
\hline Indicator_1 & -4.13 & -9.22 & Indicator_1 & 5.25 & 5.04 \\
\hline Indicator_2 & 3.41 & 4.70 & Indicator_2 & 3.29 & 3.14 \\
\hline Indicator_3 & -5.91 & 0.47 & Indicator_3 & -2.43 & -2.32 \\
\hline Indicator_4 & 33.76 & 45.37 & Indicator_4 & -0.92 & -0.88 \\
\hline Indicator_5 & 13.44 & 2.89 & Indicator_5 & 0.54 & 0 \\
\hline Indicator_6 & -3.26 & -2.04 & & & \\
\hline Indicator_7 & -0.18 & -0.14 & & & \\
\hline
\end{tabular}

\subsubsection{New Mexico}

The New Mexico state has the best energy profile compared to other three states for both production and consumption. Our criteria raise from the PCA analysis that the energy profile contains most factors which are related to the cleaner and renewable energy productions. For the consumption, in 2025 and 2050 the forecasting result is much less than other three states and the renewable and cleaner energy production increase significantly during 2025 and 2050.

\begin{tabular}{|l|l|l|l|l|l|}
\hline Consumption & 2025 & 2050 & Production & 2025 & 2050 \\
\hline Indicator_1 & -2.91 & -12.21 & Indicator_1 & 25.88 & 123.26 \\
\hline Indicator_2 & -6.45 & 7.14 & Indicator_2 & 23.81 & 108.93 \\
\hline Indicator_3 & 18.19 & -4.36 & Indicator_3 & 8.65 & 50.43 \\
\hline Indicator_4 & 3.23 & -0.96 & & & \\
\hline Indicator_5 & 9.80 & -2.08 & & & \\
\hline Indicator_6 & -10.36 & -0.08 & & & \\
\hline Indicator_7 & 10.19 & -0.76 & & & \\
\hline Indicator_8 & -2.43 & -0.04 & & & \\
\hline
\end{tabular}

\subsubsection{Texas}

Texas seems to have the much new energy to be developed. During 2025 to 2050, the consumption indicator shows that the consumption of the energy will vary during these 25 years which means maybe the development of the industries will change which may affect the different type of energy use. For the production, the renewable energy will develop during 25 years.

\begin{tabular}{|l|l|l|l|l|l|}
\hline Consumption & 2025 & 2050 & Production & 2025 & 2050 \\
\hline Indicator_1 & 36.73 & 129.11 & Indicator_1 & 90.42 & 3221.90 \\
\hline Indicator_2 & -15.48 & 59.93 & Indicator_2 & 128.24 & 4776.24 \\
\hline Indicator_3 & 50.16 & -42.73 & Indicator_3 & 43.96 & 1637.56 \\
\hline Indicator_4 & 30 & 6.35 & Indicator_4 & -10.78 & -403.76 \\
\hline Indicator_5 & 17.37 & -2.21 & & & \\
\hline Indicator_6 & -12.12 & -6.41 & & & \\
\hline Indicator_7 & 28.64 & 8.65 & & & \\
\hline
\end{tabular}

\section{Suggestions}

Based on the results of the model data analysis, we gave the following suggestions:

1) As the standards of four states are different, a gold standard of energy calculation should be established.

2) Based on the advantages of four states, the government should focus several certain kinds of energy which is sufficient within the state and corporate with other states to balance the energy production. 
3) After the analysis of energy usage of all sectors, the usage should be limited by the governments of four states and the standard should be strictly conducted.

\section{Conclusion}

The common target for four states is to minimize the tradition energy consumption and maximize the cleaner and renewable energy. To be specified, Arizona mainly depends on the oil and coal which can produce from California. Therefore, the further goal is to strengthen the cooperation between two states. For the New Mexico and California, the large production of the renewable and cleaner energy can solve the problem of energy shortage of Texas. The wind source of Texas and Arizona can provide enough electricity for four states which can be further developed in new few years as the industry has just started to grow.

\section{References}

[1] Averyt K, et.al (2011). "Freshwater Use by US Power Plants: Electricity’s Thirst for a Precious Resource”, Cambridge, MA: Union of Concerned Scientists.

[2] Anonymous (2013), "The Big Water Projects in California". California Water Impact Network. Archived from the original on 2013-10-01. Retrieved 2013-10-15.

[3] Anonymous (2016), “New Mexico groups push for more renewable energy” [online]

[4] Berg, E (2000). "Big boom predicted": oil exploration and speculation in northern Arizona, 1900-193. Journal of Arizona History, 41(1), 1-30.

[5] Meier, Fred. "The California State Water Project" (PDF). University of California, Los Angeles. Retrieved 2013-10-17.

[6] Mercado. F (2017). “The State of Mexican Renewable Energy Business in 2017”. [Online] 